\title{
Effects of a polymeric organic coagulant for industrial mineral oil wastewater treatment using response surface methodology (RSM)
}

\author{
E Kweinor Tetteh* and S Rathilal \\ Faculty of Engineering and the Built Environment, Department of Chemical Engineering, Durban University of Technology, Steve Biko Campus \\ (S4 Level 1) Box 1334, Durban 4000, South Africa
}

\begin{abstract}
In this study, treatment of a local South African oil refinery effluent using a coagulation flotation process is designed using response surface methodology (RSM). A Box-Behnken design (BBD) implementing the RSM is applied to evaluate the effects and interactions of three operating parameters, viz., $\mathrm{pH}$, coagulant dosage and flotation time, on the treatment of mineral oil wastewater (MOW). Polyacrylamide (Zetag-FS/A50), which is a water-soluble compound, is applied to enhance the adsorption mechanism and intermolecular bridging to minimise the amount of oil droplets. In addition, due to the monomeric nature and the charge density of the Zetag-FS/A50, its efficiency was evaluated to serve as an alternative coagulant for the pretreatment of the MOW. The removal of chemical oxidation demand (COD), soap oil and grease (SOG), total suspended solids (TSS) and turbidity from the MOW were used as the response variables for the coagulation flotation process. This was done with a standard dissolved air flotation jar test. The results show that the actual COD, SOG, TSS and turbidity percentage removal at optimised conditions with a coagulant dosage of $50 \mathrm{mg} / \mathrm{L}$ were $82 \%, 83 \%, 70 \%$ and $83 \%$ respectively, while the predicted response was $92 \%, 96 \%, 73 \%$ and $87 \%$ for COD, SOG, TSS and turbidity, respectively. The analysis of variance (ANOVA) showed that the proposed models are significant at a 95\% confidence level. A quadratic model was generated for response variables COD and SOG, while TSS and turbidity produced a linear model. The models fitted well with the experimental data with correlation coefficients (actual R2) of 0.94 for COD, 0.91 for SOG, 0.81 for TSS, and 0.75 for turbidity. The outcome of the study shows that the RSM has merit to optimise and identify the most important factor to control and the Zetag-FS/A50 coagulant has the potential to adsorb the oil droplets in order to enhance the treatment efficiency of the process.
\end{abstract}

Keywords: coagulation, organic coagulant, response surface methodology, soap oil and grease

\section{INTRODUCTION}

Chemo-physical treatment of industrial mineral oil wastewater (MOW) before discharge is necessary for the conservation of freshwater supplies and the protection of the environment. Petrochemical or oil contaminants in water pose a threat to the environment and water bodies, and to industrial equipment through corrosion and an increase in the cost of maintenance (Jamaly et al., 2015; Yu et al., 2017). The principal focus of addition of coagulant chemicals to physical separation processes is to effectively reduce the workload for downstream treatment. However, this has its own limitations, with high sludge production and a high cost of operational chemical procurement (Hosny et al., 2016; Kweinor Tetteh et al., 2017). The selection of the right type of polymeric coagulant for application depends on its sensitivity and operating conditions, applied in the right proportion to initiate neutralization, stability and mobility of the colloidal oil droplets in order to enhance treatment effectiveness (Hosny et al., 2016). The removal of the targeted contaminants in the MOW, the type of coagulant, coagulant dosage, $\mathrm{pH}$ and flotation time also play an important role to enhance the treatability and efficiency (Zouboulis and Avranas, 2000; Daud et al., 2015). Therefore, the Box-Behnken design (BBD) of experiment was adapted from the response surface methodology (RSM) to optimise the relevant operating parameters in order to reduce the researcher's experimental workload and high cost of chemical usage, and to avoid uncertainty on industrial application

\footnotetext{
* To whom all correspondence should be addressed.

e-mail: ektetteh34@gmail.com

Received 25 February 2017; accepted in revised form 16 March 2018
}

(Chavalparit and Ongwandee, 2009; Li et al., 2016; Tetteh and Rathilal, 2017).

Chemical and physical techniques, such as the coagulation flotation mechanism, have been widely used in industrial wastewater systems for separating oil from water, due to their effectiveness (Mousa and Hadi, 2016). However, coagulation flotation is a complicated process, which involves a series of physical-chemical interactions for the removal of contaminants, depending on the type of coagulant (Diya'uddeen et al., 2011; Daud et al., 2015). Coagulation, which is usually the first stage in a pre-treatment process, neutralises the charge of the oil droplets and forces them to agglomerate.

A study carried out by Al-Shamrani et al. (2002) found that, by using coagulation as a chemical pre-treatment of water quality of $100 \mathrm{mg} / \mathrm{L}$ of oil, the base oil can easily be removed by the flotation process. Also, inducing of dissolved air bubbles and the coagulated oil droplet floc enhance the buoyancy force exerted by the flotation process, enabling the oil droplet to float and be separated (Hosny et al. 2016). To bring about attraction and adsorption of oil droplets to the surface flotation tank, for effective separation, requires the application of a polymeric organic coagulant. This is a new hetero-coagulation technique for industrial wastewater treatment, especially for wastewaters with suspended or emulsified oil, whose organic phase prefers to float than to settle (Vijayaraghavan et al., 2011; Jamaly et al., 2015). There are some drawbacks to conventional wastewater treatment associated with the use of inorganic coagulants (e.g. aluminium and iron salts), such as high volumes of sludge generation, and high $\mathrm{pH}$ and dosage requirements (Hosny et al., 2016; Kweinor Tetteh et al., 2017; Yu et al., 2017). Therefore, application of polymeric organic coagulants has become the alternative method to reduce the high sludge volumes generated when utilising inorganic coagulants. 
The molecules of the organic polymers are held together by recapping covalent bonds; their ionisation functional group is categorised based on the electric charge they carry, viz., positively charged or cationic polymers and negatively charged or anionic polymers. In addition, the charged or ionic polymers are usually called polyelectrolytes while those with no charge are known as non-ionic polymers (Li et al., 2008; Vedoy and Soares, 2015). In general, the main mechanism of coagulation is charge neutralisation and bridging of the oil micro-droplet flocs to produce macro-droplet flocs, which depends on the molecular charge and the charge density. Some of the polymers used for coagulation are of low molecular weight with high cationic charge density, for example, hydrolysed polyaluminium sulphate (PAS), polyacrylamide, melamine formaldehydes, polyamine, polyacrylamides (Zetag-FS/A50) and polydiallydimethyl ammonium chloride (polyDADMAC) (Zouboulis and Avranas, 2000; Bolto and Gregory, 2007; Li et al., 2008; Guan et al., 2014; Oliveira et al., 2014; Kweinor Tetteh et al., 2017). There has recently been extensive and ongoing work looking for an alternative coagulant for chemical treatment that is capable of meeting more stringent treatment standards. Some limitations include metal salts presence in the discharge effluent, high procurement cost, water quality not meeting the standard for reuse and sludge management problems arising from the use of chemicals (coagulants) (Chollom et al., 2015; Jamaly et al., 2015; Vedoy and Soares, 2015; Yu et al., 2017).

Polymeric organic coagulant usage in MOW treatment, due to the presence of hydrolysed metal salts, is sensitive to $\mathrm{pH}$ and reduction of the metal salts in the discharge water. In addition, its molecular weight and degradability varies, aiding in separation of solid-liquids (emulsified oil) whose molecules does not settle easily (Vijayaraghavan et al., 2011; Yu et al., 2017). As part of this study, a field study on a local South Africa wastewater treatment process was conducted and an expert consulted at a local water treatment plant reported, based on experience, that Zetag-FS/A50 has super-surfactant merits when applied in treating industrial wastewater. However, it has some drawbacks for the environment when attention is not paid to over- or under-dosage, such as (a) re-dispersion of impurities, (b) increase in sludge formation and (c) high turbidity (Bolto and Gregory, 2007; Guan et al., 2014; Oliveira et al., 2014). It is therefore important to pay attention to the coagulant dosage throughout the treatment process.

With the rapid development in wastewater treatment technologies, where optimisation is of great concern in the production industries, many researchers are looking for the most important tool for process optimisation, in order to enhance, maximise or minimise the response of the water quality or property (Chavalparit and Ongwandee, 2009; Khannous et al., 2011; Li et al., 2016; Pambi and Musonge, 2016). RSM is a dynamic and important tool for the design of experiments (DOE) to evaluate the relationship that exists between process input and output variables. A series of runs are usually made by effecting changes to the input variables. After data collection, statistical analysis and modelling is done to identify the reason for the changes in the output variables. Inaccuracy that occurs in physical experiments is associated with measured errors, while in computer simulations numerical noise and round-off errors occur when an iteration does not converge completely. In RSM, errors are assumed as random; hence, strategy is adapted to select the point where the response is evaluated. In respect of this, for the optimal design, the input variables which have a large impact are identified and a response model for predictions or for further investigations is obtained (Li et al., 2016). The optimisation of multiple factors in the conventional method (varying one factor and keeping others fixed at specific conditions) has limitations, such that it ignores the interactions amongst the variables. This is not only time consuming, but also renders the method incapable of reaching the true optimum conditions. RSM has been successfully applied in optimising wastewater treatment processes. According to Li et al. (2016), application of RSM for process optimisation indicates the area within the design region where a desirable result can be attained. Pambi and Musonge (2016) used RSM to optimise sugar refinery wastewater treatment process, and reported that RSM offers an alternative way to optimise a process for effective treatment..

This study focused on the relationship between treatment response for MOW and operating parameters of the coagulation flotation process, which forms the basis for promoting the application of Zetag-FS/A50 for chemical treatment of industrial oil-water. The RSM using BBD of experiment is employed to optimise and evaluate the most influential factors, from $\mathrm{pH}$, coagulant dosage and flotation time. This aimed to maximise the removal of chemical oxidation demand (COD), soap oil and grease (SOG), total suspended solids (TSS) and turbidity. To assess the accuracy of the model, the predicted value was compared with the experimental results to find the optimal operating parameter.

\section{MATERIAL AND METHODS}

\section{Coagulation flotation process}

The industrial mineral oil wastewater obtained from a local South Africa oilfield was characterized as follows: high content of COD (11 $978 \mathrm{mg} / \mathrm{L})$, SOG (1 218mg/L), TSS (1 $067 \mathrm{mg} / \mathrm{L})$, and turbidity $(2753 \mathrm{mg} / \mathrm{L})$ (Kweinor Tetteh et al., 2017). All of the analyses were done using the protocols of standard methods for analysis of water and wastewater (APHA, 2012). The COD was analysed using a Hanna HI 83099 COD and multiparameter photometer. The TSS analysis was performed with a Hach DR890 portable calorimeter. Turbidity was observed with a Hach $2100 \mathrm{~N}$ turbidity meter. The South Africa Bureau of Standards Standard Method 1051 was used to analysis the SOG. The polyacrylamide (Zetag-FS/ A50) was supplied by Rheochem (Pty) Ltd, South Africa. With the BBD of experiment, adjustment of the $\mathrm{pH}(4 ; 5 ; 6)$ was done with $1.0 \mathrm{M} \mathrm{H} 3 \mathrm{PO} 4$. The jar test experiment was done using a DAF jar tester with six $1 \mathrm{~L}$ rectangular jars and a $8 \mathrm{~L}$ recycle air saturator operated at a pressure of $350 \mathrm{kPa}$. After the addition of the required coagulant dosage (30; 40; $50 \mathrm{mg} / \mathrm{L}$ ), the mixture was mixed at a speed of $250 \mathrm{r} / \mathrm{min}$ for $2 \mathrm{~min}$. The speed was then reduced to $30 \mathrm{r} / \mathrm{min}$ for $15 \mathrm{~min}$ to promote floc growth. The setup (Fig. 1) was maintained for the flotation time prescribed by the DOE $(10 ; 15 ; 20 \mathrm{~min})$.

\section{Response surface methodology (RSM)}

RSM is a collection of mathematical and statistical tools, usually used to improve process optimisation. In addition, it is used to evaluate the relative significant effects of multiple factors in complex interactions. The experimental runs were designed to obtain the desired response information through the manipulation of the input variables in a cost-effective manner. Design Expert 10.0.3 software was used for the 


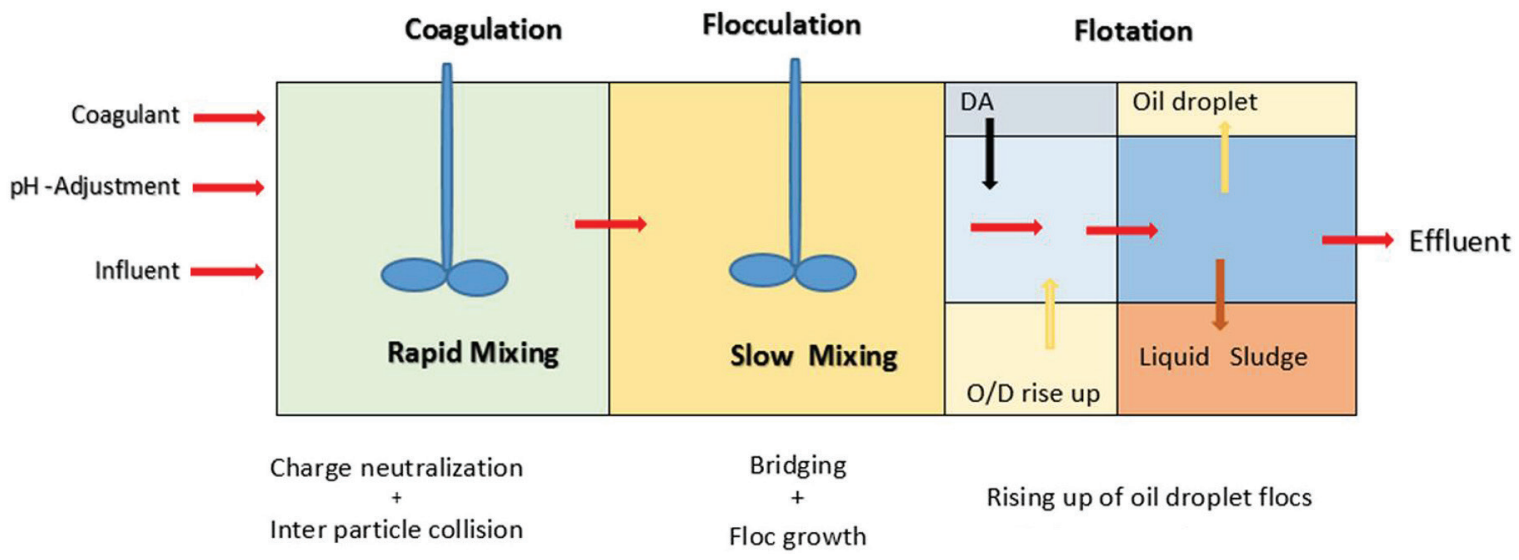

Figure 1

Coagulation flotation process setup at a constant air saturator pressure of $350 \mathrm{kPa}$. Note: DA - dissolved air; O/D - oil droplets

process design and formulation of variables. The BBD adapted from the RSM was used to study the effects of the variables at a minimum number of experimental runs covered by the design space. With 3 levels and 3 factors $\left(\mathrm{pH}\left(X_{1}\right)\right.$, coagulant dosage $\left(X_{2}\right)$ and flotation time $\left.\left(X_{3}\right)\right), 17$ experimental trials with 5 centre points were obtained. The experiments were carried out in a random order to avoid unexpected variations (errors) associated with the level settings, and the yield compared with that predicted. Yields such as COD $\left(Y_{1}\right)$, SOG $\left(Y_{2}\right)$, TSS $\left(Y_{3}\right)$ and turbidity $\left(Y_{4}\right)$ were calculated using Eq. 1 .

$$
Y_{\mathrm{n}}=\left(\frac{y_{0}-y_{1}}{y_{0}}\right) \times 100 \%
$$

where $Y_{n}, y_{0}$ and $y_{1}$, respectively, represent the response variable, initial and final values for the coagulation flotation process.

\section{RESULTS AND DISCUSSION}

The effectiveness of the polyacrylamide (Zetag-FS/A50) as a coagulant was measured by the water quality or percentage removal of contaminants. Zetag-FS/A50, which is a type of polymeric organic coagulant, was effective in separating oilin-water emulsions. The dissolved monomers of Zetag-FS/A50 are induced to polymerise through the action of free radicals. The relationship between the 3 input variables, namely, $\mathrm{pH}$ $\left(X_{1}\right)$, coagulant dosage $\left(X_{2}\right)$ and flotation time $\left(X_{3}\right)$, and the 4 responses $\left(\operatorname{COD}\left(Y_{1}\right)\right.$, SOG $\left(Y_{2}\right)$, TSS $\left(Y_{3}\right)$ and turbidity $\left.\left(Y_{4}\right)\right)$ for the coagulation flotation process was analysed with RSM. The experimental data collected were modelled to obtain significant model terms for a good fit in each model response.

From Table 1, the results obtained from the design matrix show that the Zetag-FS/A50 was effective in the removal of

\begin{tabular}{|c|c|c|c|c|c|c|c|c|}
\hline \multicolumn{9}{|c|}{$\begin{array}{c}\text { TABLE } 1 \\
\text { Experimental design and responses }\end{array}$} \\
\hline \multirow{2}{*}{$\begin{array}{l}\text { Random } \\
\text { runs }\end{array}$} & \multirow{2}{*}{$\begin{array}{l}\text { Standard } \\
\text { runs }\end{array}$} & \multicolumn{3}{|c|}{$(X)$ Input variables } & \multicolumn{4}{|c|}{ (Y) Response yield efficiency } \\
\hline & & $\mathrm{pH}$ & $\begin{array}{l}\text { Coagulant dose } \\
(\mathrm{mg} / \mathrm{L})\end{array}$ & $\begin{array}{l}\text { Flotation } \\
\text { time (min) }\end{array}$ & $\begin{array}{l}\text { COD } \\
(\mathrm{mg} / \mathrm{L})\end{array}$ & $\begin{array}{l}\text { SOG } \\
(\mathrm{mg} / \mathrm{L})\end{array}$ & $\begin{array}{l}\text { Turbidty } \\
\text { (NTU) }\end{array}$ & $\begin{array}{c}\mathrm{TSS} \\
(\mathrm{mg} / \mathrm{L})\end{array}$ \\
\hline 14 & 1 & 5 & 40 & 15 & 87 & 91 & 80 & 71 \\
\hline 15 & 2 & 5 & 40 & 15 & 84 & 90 & 83 & 70 \\
\hline 11 & 3 & 5 & 30 & 20 & 80 & 70 & 73 & 63 \\
\hline 3 & 4 & 4 & 50 & 15 & 84 & 87 & 79 & 68 \\
\hline 6 & 5 & 6 & 40 & 10 & 79 & 75 & 78 & 66 \\
\hline 13 & 6 & 5 & 40 & 15 & 84 & 86 & 81 & 69 \\
\hline 12 & 7 & 5 & 50 & 20 & 85 & 88 & 84 & 69 \\
\hline 4 & 8 & 6 & 50 & 15 & 81 & 88 & 83 & 67 \\
\hline 7 & 9 & 4 & 40 & 20 & 77 & 83 & 83 & 68 \\
\hline 17 & 10 & 5 & 40 & 15 & 82 & 90 & 85 & 68 \\
\hline 8 & 11 & 6 & 40 & 20 & 77 & 84 & 84 & 67 \\
\hline 1 & 12 & 4 & 30 & 15 & 75 & 73 & 71 & 61 \\
\hline 5 & 13 & 4 & 40 & 10 & 79 & 84 & 80 & 66 \\
\hline 2 & 14 & 6 & 30 & 15 & 78 & 72 & 72 & 65 \\
\hline 10 & 15 & 5 & 50 & 10 & 83 & 89 & 84 & 69 \\
\hline 9 & 16 & 5 & 30 & 10 & 79 & 81 & 74 & 62 \\
\hline 16 & 17 & 5 & 40 & 15 & 83 & 88 & 82 & 61 \\
\hline
\end{tabular}


the contaminants, which are given as COD (80-90\%), SOG (70-90\%), TSS (70-85\%), and turbidity (60-75\%). This occurred via the mechanism of flocculation of the oil droplets and the repulsion between the oil droplets and air bubbles (Saritha et al., 2015).

\section{Response/water quality models}

In modelling and analysing how a process response is being affected by the input variables, optimising of this response requires a mathematical and statistical tool, which was provided in this case by the RSM. The main purpose of RSM is to understand and evaluate the effect of multiple parameters and their interactions with each other in bringing about the response(s). The output parameters (responses) were expressed as functions of the input process parameters. A second-order model was identified which fitted the response variables; this was in the form of a quadratic polynomial equation expressed as;

$$
y=b_{0}+\sum_{n=1}^{n} b_{i} x_{i}+\sum_{i=1}^{n} b_{i i} x_{i}+\sum_{i}^{i<j, k} \sum_{j, k} b_{i j k} x_{i} x_{j} x_{k}
$$

Where, $y$ is the response variable to the model input variables; $x_{\mathrm{i}}, x_{\mathrm{j}}$ and $x_{\mathrm{k}}$. The terms $b_{0}, b_{\mathrm{i}}, b_{\mathrm{ii}}$ and $b_{\mathrm{ijk}}$ represent the offset terms or the intercept, the linear coefficient, quadratic coefficient and the $(i j k)^{\text {th }}$ interactive coefficient, respectively.

The increase in removal of COD, SOG, TSS and turbidity was found to be most affected by polymeric organic coagulant dosage. The coagulant dosage accelerated oil droplet floc formation, with an increase in buoyant density to avoid breaking of the flocs during flotation. The adjustment of the $\mathrm{pH}$ contributed to the difference in the surface charge of the $\mathrm{OH}^{-}$and $\mathrm{H}^{+}$ions present in the oil emulsion. This demonstrated concurrent charging of the oil droplets assisting them to agglomerate (Al-Shamrani et al., 2002). It was found that the $\mathrm{pH}$ and the flotation time had less influence on the efficiency of the Zetag-FS/A50 in removal of the contaminants. This is because polymeric organic coagulants are effective at a wide range of $\mathrm{pH}$ (Vedoy and Soares, 2015). Although the coagulant dosage was found to be the most influential factor, under-dose or overdose can hinder the objective of reducing the cost associated with chemical usage or improving water quality (Saritha et al., 2015). In this case, the $\mathrm{pH}$ and the flotation time were kept at constant optimum conditions of 5 and $15 \mathrm{~min}$, respectively. The coagulant dosage was then evaluated at 30,40 and $50 \mathrm{mg} / \mathrm{L}$ to verify the predictive ability of the derived models.

\section{ANOVA}

This study used an experimental data approach to develop the response models in order to establish the relationship between the input variables and the response. The performance and sensitivity of the models were evaluated using analysis of variance (ANOVA). The coefficient of the determined actual $R^{2}$ and the predicted $R^{2}$ was also assessed in order to select the best models for the various responses. The correlation of the empirical relationship between the percentage residual of the output responses and the input process parameters was expressed by the following model equations:

$$
\begin{aligned}
& \operatorname{COD}\left(Y_{1}\right)=-19.75+40.38 X_{1}-1.28 X_{2}+2.33 X_{3}-4 X_{1}^{2}+0.02 X_{2}^{2}-0.08 X_{3}^{2} \\
& \operatorname{SOG}\left(Y_{2}\right)=-101.11+41.78 X_{1}+3.63 X_{2}-4.33 X_{1}^{2}-0.034 X_{2}^{2}
\end{aligned}
$$

$$
\begin{aligned}
& \text { TSS }\left(Y_{3}\right)=55.42+0.625 X_{2} \\
& \text { Turbidity }\left(Y_{4}\right)=45.35+0.56 X_{2}
\end{aligned}
$$

where $X_{1}, X_{2}$ and $X_{3}$ represent $\mathrm{pH}$, coagulant dosage $(\mathrm{mg} / \mathrm{L})$ and flotation time (min).

The model equations $(3 ; 4 ; 5 ; 6)$ are limited to the ranges considered for $4<X_{1}<6 ; 30<X_{2}<50$; and $10<X_{3}<20$. The ANOVA for the response models shows that the magnitude of the $F$-test and the $P$-value was less than 0.05 ; thus, the model is significant.

Table 2 shows the statistical analysis of the derived models for the various responses. The best model was selected based on how low the standard deviation or how high the actual $R^{2}$ and predicted $R^{2}$ values are for each corresponding water quality. The quadratic models were selected for COD and SOG with standard deviation, actual and predicted $R^{2}$ values of 1.7, 0.94, 0.84 , and $3.26,0.91,0.90$, respectively. Although in all cases, the cubic model shows high actual $R^{2}$ values, it lacks the ability for prediction and hence was not considered. In terms of turbidity and TSS, the most appropriate model considered was the linear model with $2.55,0.75,0.68$, and $2.46,0.81,0.66$, as the standard deviation, actual and predicted $R^{2}$ values, respectively.

\section{The response three-dimensional (3D) plots}

The three-dimensional (3D) contour graphs are a visual representation of the interactions and variation of the factors in the models. The response surface obtained from the BBD model shows that the optimum levels were closer to the directions of maximum contaminant removal. Figures 2 and 3 show the quadratic model fitting responses while Figs 4 and 5 show the linear model responses. In all cases, the flotation time was kept constant, while the $\mathrm{pH}$ and coagulant dosage was varied. In this study, the $\mathrm{pH}\left(X_{1}\right)$ effective region was identified as 4.5 to 5.5 and that of coagulant dosage $\left(X_{2}\right)$ as 40 to $50 \mathrm{mg} / \mathrm{L}$. At a constant $\mathrm{pH}$ of 5, effective removal of COD and SOG was observed, but the $\mathrm{pH}$ had no significant effect on TSS and turbidity removal, unlike coagulant dosage.

\begin{tabular}{|l|l|c|c|c|}
\hline \multicolumn{5}{|c}{ TABLE 2 } \\
\hline \multirow{2}{*}{ Responses } & Model source & $\begin{array}{c}\text { Standard } \\
\text { deviation }\end{array}$ & Actual $R^{2}$ & Predicted $R^{2}$ \\
\hline \multirow{5}{*}{ COD } & Linear & 3.12 & 0.64 & 0.32 \\
\cline { 2 - 5 } & 2FI & 3.52 & 0.65 & -0.48 \\
\cline { 2 - 5 } & Quadratic & 1.70 & 0.94 & 0.84 \\
\cline { 2 - 5 } & Cubic & 1.87 & 0.96 & N/A \\
\hline \multirow{5}{*}{ SOG } & Linear & 4.78 & 0.62 & 0.37 \\
\cline { 2 - 5 } & 2FI & 5.01 & 0.68 & 0.04 \\
\cline { 2 - 5 } & Quadratic & 3.26 & 0.91 & 0.90 \\
\cline { 2 - 5 } & Cubic & 1.67 & 0.99 & N/A \\
\hline \multirow{5}{*}{ TSS } & Linear & 2.46 & 0.81 & 0.66 \\
\cline { 2 - 5 } & 2FI & 2.61 & 0.83 & 0.45 \\
\cline { 2 - 5 } & Quadratic & 1.90 & 0.79 & 0.53 \\
\cline { 2 - 5 } & Cubic & 1.92 & 0.76 & N/A \\
\hline \multirow{5}{*}{ Turbidity } & Linear & 2.55 & 0.75 & 0.68 \\
\cline { 2 - 5 } & 2FI & 2.68 & 0.74 & 0.66 \\
\cline { 2 - 5 } & Quadratic & 3.01 & 0.71 & 0.67 \\
\cline { 2 - 5 } & Cubic & 3.96 & 0.72 & N/A \\
\hline
\end{tabular}




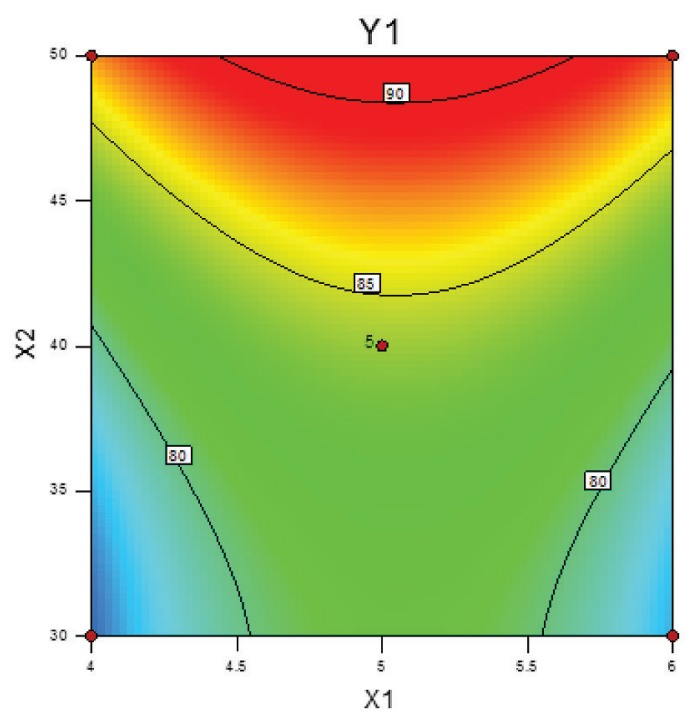

Figure 2

Response surface 3D plot of the $C O D\left(Y_{1}\right)$ model at a constant flotation time $\left(\mathrm{X}_{3}\right)$ of $15 \mathrm{~min}$

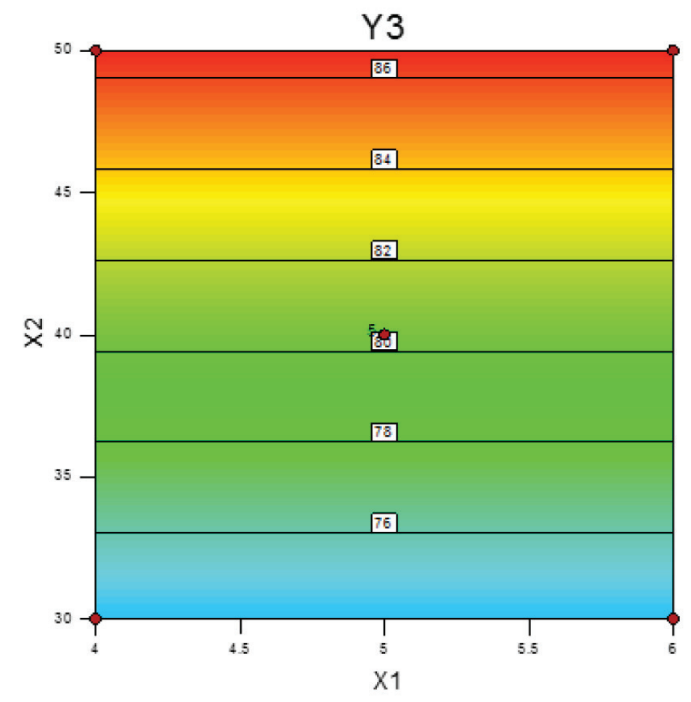

Figure 4

Response surface 3D plot of the TSS $\left(\mathrm{Y}_{3}\right)$ model at a constant flotation time $\left(\mathrm{X}_{3}\right)$ of $15 \mathrm{~min}$

\section{Comparing experimental and model predicted results}

In comparing the experimental results to the response models predicted values, the result shows that increasing coagulant dosage enhances the removal of the contaminants from the MOW. In Fig. 6, it can be seen that at a coagulant dosage of $50 \mathrm{mg} / \mathrm{L}$, about $80 \%$ and above of the COD and SOG were removed in the actual experiment. The model predictions at coagulant dosage of $40 \mathrm{mg} / \mathrm{L}$ was also about $80 \%$ for COD and the SOG removal, which is almost in agreement with the experimental results. This demonstrated that the optimum operation parameters obtained can be used to safeguard the oil-water separation process, improve the effluent quality, and save time and cost.

Figure 7 shows that increasing coagulant dosage increases percentage removal of TSS and turbidity. Although the model may predict high removals of the contaminants, this may not be physically possible as shown from the experiments.

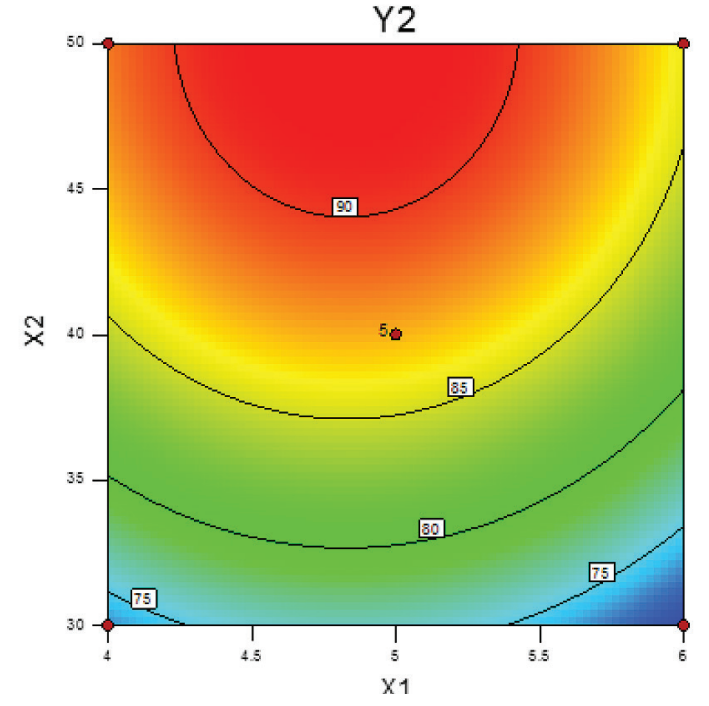

Figure 3

Response surface 3D plot of the SOG $\left(\mathrm{Y}_{2}\right)$ model at a constant flotation time $\left(\mathrm{X}_{3}\right)$ of $15 \mathrm{~min}$

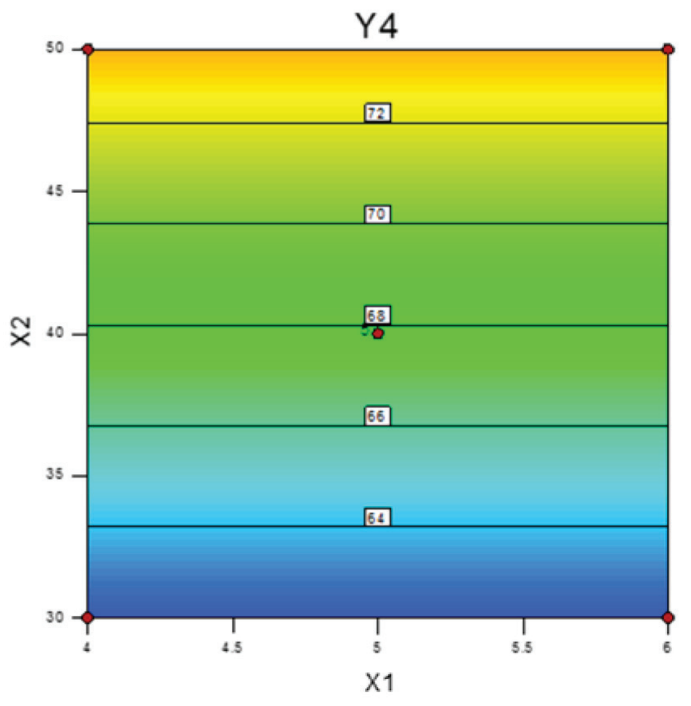

Figure 5

Response surface 3D plot of the turbidity $\left(\mathrm{Y}_{4}\right)$ model at a constant flotation time $\left(\mathrm{X}_{4}\right)$ of $15 \mathrm{~min}$

However, the results showed an excellent agreement between the model predicted values and experimental data for the different coagulant dosages. In addition, the coagulant dosage was found to be the sole input variable that affected the removal of TSS and turbidity.

\section{CONCLUSION}

The adaptation of the BBD from the RSM to evaluate the efficiency of the polymeric organic coagulant has important implications in optimising the interactive factors that affect the coagulation flotation process for the separation of oil and water for reuse.

The following were the outcomes:

- The characterization of the MOW is essential to ensure the efficiency of the polyacrylamide (Zetag-FS/A50) and to meet 


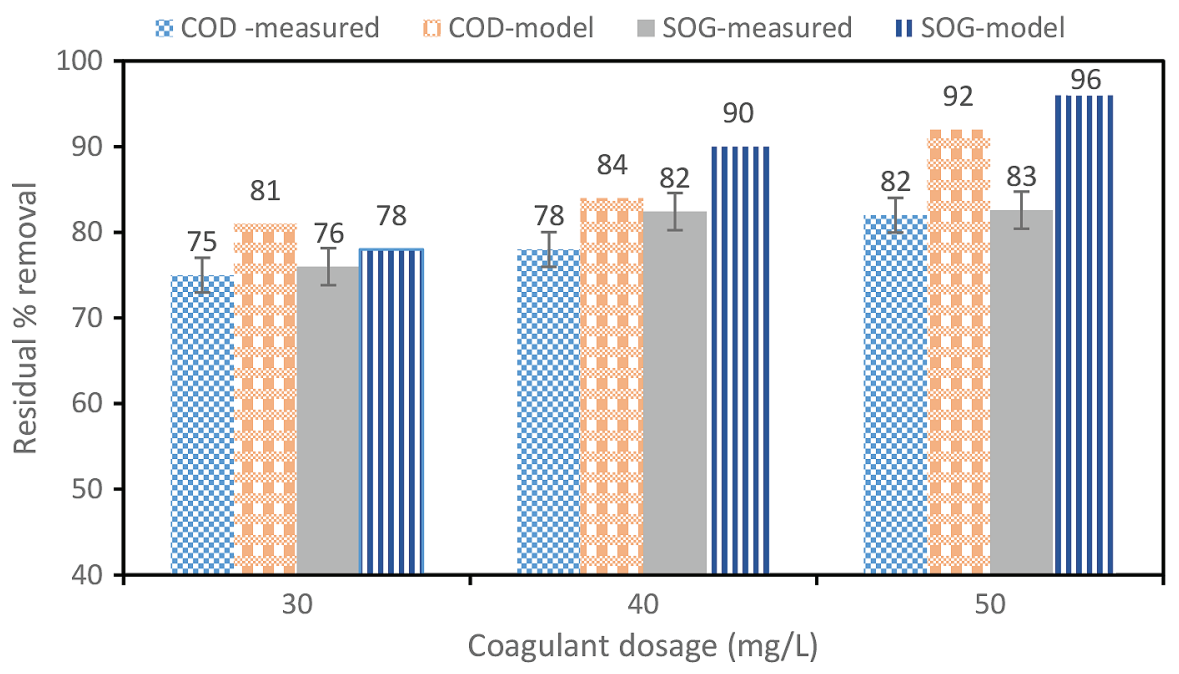

Figure 6

Effect of coagulant dosage and predictions by the quadratic models for \% removal of COD and SOG at a pH of 5 and flotation time of $15 \mathrm{~min}$

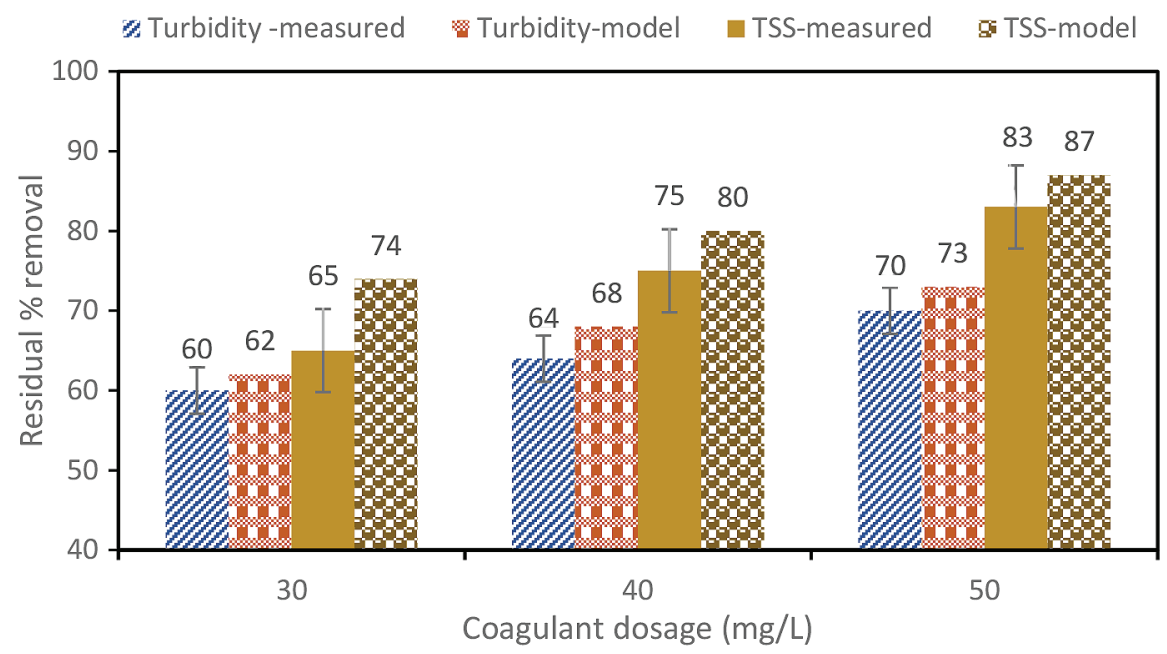

Figure 7

Effect of coagulant dosage and predictions by the linear models for \% removal of TSS and Turbidity at a pH of 5 and flotation time of 15 min

the trade-off for the effluent discharge. At the optimum conditions of $\mathrm{pH} 5$, coagulant dosage of $40 \mathrm{mg} / \mathrm{L}$ and flotation time of $15 \mathrm{~min}$, the model predicted above $80 \%$ removal of the contaminants, which was similar to the experimental results at a coagulant dosage of $50 \mathrm{mg} / \mathrm{L}$. The coagulant dosage was found to be the most influential factor, and proactive monitoring of the dosage will ensure the optimal process operation for effective reduction of the contaminants.

- RSM serves as a reliable statistical tool for modelling experimental data. This serves as a means of optimizing the process in a shorter time period, reducing experimental cost, and evaluating and making decisions for the process response feedback. The response surface models showed the effect of each input variable on the trend of all the responses at a confidence level of 0.95 when using ANOVA to assess fit. The validation of the response models with additional experimental data confirmed the model's reliability for use within the designed range of parameters. RSM is useful and therefore recommended for future work on optimisation and process improvement.

\section{ACKNOWLEDGEMENTS}

The authors wish to thank FFS Refiners Research and

Development Department and Umgeni Water Process Evaluation Facility (PEF), South Africa, for their joint support in this project.

We also acknowledge the facilitators at a workshop on scientific writing, arranged by Young Water Professionals, South Africa, in cooperation with IWA, and supported by the Water Research Commission.

\section{REFERENCES}

AL-SHAMRANI A, JAMES A and XIAO H (2002) Destabilisation of oil-water emulsions and separation by dissolved air flotation. Water Res. 36 (6) 1503-1512. https://doi.org/10.1016/ S0043-1354(01)00347-5

APHA/AWWA/WEF (2012) Standard Methods for the Examination of Water and Wastewater. APHA/AWWA/WEF, Washington, DC.

BOLTO B and GREGORY J (2007) Organic polyelectrolytes in water treatment. Water Res. 41 (11) 2301-2324. https://doi.org/10.1016/j. watres.2007.03.012 
CHAVALPARIT O and ONGWANDEE M (2009) Optimizing electrocoagulation process for the treatment of biodiesel wastewater using response surface methodology. J. Environ. Sci. 21 (11) 1491-1496. https://doi.org/10.1016/S1001-0742(08)62445-6

CHOLLOM MN, RATHILAL S, PILLAY VL and ALFA D (2015) The applicability of nanofiltration for the treatment and reuse of textile reactive dye effluent. Water SA 41 (3) 398. https://doi.org/10.4314/ wsa.v4li3.12

DAUD Z, AWANG H, LATIF AAA, NASIR N, RIDZUAN MB and AHMAD Z (2015) Suspended solid, color, COD and oil and grease removal from biodiesel wastewater by coagulation and flocculation processes. Procedia Soc. Behav. Sci. 195 2407-2411. https://doi. org/10.1016/j.sbspro.2015.06.234

DIYA'UDDEEN BH, DAUD WMAW and AZIZ AA (2011) Treatment technologies for petroleum refinery effluents: a review. Process Saf. Environ. Protect. 89 (2) 95-105. https://doi.org/10.1016/j.psep.2010.11.003

GUAN Q, ZHENG H, ZHAI J, ZHAO C, ZHENG X, TANG X, CHEN W and SUN Y (2014) Effect of template on structure and properties of cationic polyacrylamide: characterization and mechanism. Ind. Eng. Chem. Res. 53 (14) 5624-5635. https://doi.org/10.1021/ie404116k

HOSNY R, FATHY M, RAMZI M, ABDEL MOGHNY T, DESOUKY SEM and SHAMA SA (2016) Treatment of the oily produced water (OPW) using coagulant mixtures. Egypt. J. Petrol. 25 (3) 391-396. https://doi.org/10.1016/j.ejpe.2015.09.006

JAMALY S, GIWA A and HASAN SW (2015) Recent improvements in oily wastewater treatment: Progress, challenges, and future opportunities. J. Environ. Sci. 37 15-30. https://doi.org/10.1016/j.jes.2015.04.011

KHANNOUS L, ABID D, GHARSALLAH N, KECHAOU N and MIHOUB NB (2011) Optimization of coagulation-flocculation process for pastas industry effluent using response surface methodology. Afr. J. Biotechnol. 10 (63) 13823-13834. https://doi. org/10.5897/AJB11.1142

KWEINOR TETTEH E, RATHILAL S and ROBINSON K (2017) Treatment of industrial mineral oil wastewater - effects of coagulant type and dosage. Water Pract. Technol. 12 (1) 139-145. https://doi.org/10.2166/wpt.2017.021

LI H, LONG J, XU Z and MASLIYAH JH (2008) Effect of molecular weight and charge density on the performance of polyacrylamide in low-grade oil sand ore processing. Can. J. Chem. Eng. 86 (2) 177-185. https://doi.org/10.1002/cjce.20029

LI N, HU Y, LU Y-Z, ZENG RJ and SHENG G-P (2016) Multiple response optimization of the coagulation process for upgrading the quality of effluent from municipal wastewater treatment plant. Sci. Reports 6 https://doi.org/10.1038/srep26115

MOUSA KM and HADI HJ (2016) Coagulation/flocculation process for produced water treatment. URL: http://inpressco.com/ category/ijcet; http://inpressco.com/wp-content/uploads/2016/04/ Paper28551-555.pdf (Accessed 20 ${ }^{\text {th }}$ July, 2017).

OLIVEIRA C, RODRIGUES RT and RUBIO J (2014) Operating parameters affecting the formation of kaolin aerated flocs in water and wastewater treatment. CLEAN Soil Air Water 42 (7) 909-916. https://doi.org/10.1002/clen.201300050

PAMBI R and MUSONGE P (2016) Application of response surface methodology (RSM) in the treatment of final effluent from the sugar industry using Chitosan. WIT Trans. Ecol. Environ. 209 209-219. https://doi.org/10.2495/WP160191

SARITHA V, SRINIVAS N and SRIKANTH VN (2015) Analysis and optimization of coagulation and flocculation process. Appl. Water Sci.

TETTEH EK and RATHILAL S (2017) Application of response surface methodology (RSM)-reduction of industrial wastewater chemical oxygen demand. In: CBU International Conference Proceedings 1226-1232. https://doi.org/10.12955/cbup.v5.1101

VEDOY DR and SOARES JB (2015) Water-soluble polymers for oil sands tailing treatment: A review. Can. J. Chem. Eng. 93 (5) 888-904. https://doi.org/10.1002/cjce.22129

VIJAYARAGHAVAN G, SIVAKUMAR T and KUMAR AV (2011) Application of plant based coagulants for waste water treatment. Int. J. Adv. Eng. Res. Stud. 1 (1) 88-92.

YU L, HAN M and HE F (2017) A review of treating oily wastewater. Arab. J. Chem. 10 S1913-S1922. https://doi.org/10.1016/j. arabjc.2013.07.020

ZOUBOULIS AI and AVRANAS A (2000) Treatment of oil-in-water emulsions by coagulation and dissolved-air flotation. Colloids Surf. A: Physicochem. Eng. Aspects 172 (1) 153-161. https://doi. org/10.1016/S0927-7757(00)00561-6 